\title{
Tendencias del mercado de suelo urbano en periodo largo. Concepción, Chile. 1989-2018
}

\author{
Héctor Gaete Feres ${ }^{1}$ \\ Recibido: 11-12-2020 | en su versión final: 28-02-2021
}

Resumen

\begin{abstract}
Desde hace 40 años en Chile la economía es abierta, opera por el libre mercado, el Estado ejerce un rol subsidiario. En ese contexto, la opacidad del mercado de suelos constituye un problema central por el alto riesgo para la acción eficiente de la planificación urbana, la gestión inmobiliaria y la provisión de viviendas. De allí que su conocimiento es de crucial importancia para garantizar transparencia. De otra parte, los territorios regionales tienen particularidades y aspectos comunes por localización y la gestión urbana local. Se estudió el caso del Gran Concepción en Chile con datos de ofertas de suelo 1989-2018 y por correlaciones se revisó el comportamiento de las variables buscando regularidades. Para tendencias se proyectó al 2030 mediante previsiones con el modelo Holt-Winters. Se detectó una alta asociación entre variables, un mercado consolidado con estructura urbana jerarquizada con tendencia a la baja en ofertas y superficie ofrecida, fuerte tendencia al alza de precios creciendo por sobre los resultados de la economía y sus proyecciones. Se evidenció que la configuración del precio no es sólo por la acción de la oferta y demanda directa, sino que intervienen en su conformación otros componentes como son la configuración del "precio adelantado" ante anuncios gubernamentales y el "precio de impacto" ante desastres de la naturaleza y por acción humana. Se observó además que es posible de detectar la maduración y robustez del mercado en cuanto se produce el desacople de variables claves como el precio, respecto de la oferta en cantidad y/o en volumen.
\end{abstract}

Palabras clave: Mercado de suelo urbano; urbanismo; gestión y valoración urbana

Citación

Gaete, H. (2021). Tendencias del mercado de suelo urbano en periodo largo. Concepción Chile. 1989-2018. ACE: Architecture, City and Environment, 16(46), 9946. DOI: http://dx.doi.org/10.5821/ace.16.46.9946

\section{Long-Term Urban Land Market Trends. Concepcion, Chile. 1989- 2018}

Abstract

For 40 years in Chile, the economy has been open, it operates through the free market; the State has played a subsidiary role. In this context, the opacity of the land market constitutes a central problem due to the high risk for the efficient action of urban planning, real estate management, and the provision of housing. Hence, your knowledge is of crucial importance to ensure transparency. On the other hand, regional territories have particularities and common aspects due to their location and local urban management. The case of Gran Concepción in Chile was studied with data on land offers 1989-2018 and by correlations, the behavior of the variables was reviewed looking for regularities. For trends, it was projected to 2030 through forecasts with the Holt-Winters model. A high association between variables was detected, a consolidated market with a hierarchical urban structure with a downward trend in offers and surface offered, a strong upward trend in prices growing above the results of the economy and its projections. It was evidenced that the configuration of the price is not only due to the action of direct supply and demand, but other components such as the configuration of the "advance price" in the face of government announcements and the "impact price" in the event of disaster nature and due to human action. It was also observed that it is possible to detect the maturity and robustness of the market as soon as the decoupling of key variables such as price occurs, with respect to the supply in quantity and volume.

Keywords: Urban land market; town planning; urban management and valuation

${ }^{1}$ Doctor Arquitecto, Departamento Planificación y Diseño Urbano, Facultad de Arquitectura, Construcción y Diseño, Universidad del Bío-Bío, Concepción-Chile (ORCID 0000-0003-2901-9410, Scopus Author ID: 56266808800, WoS ResearcherID: AAG-7458-2021). Correo de contacto: hgaete@ubiobio.cl 


\section{Introducción}

Es de particular relevancia el que actualmente en Chile el 87,8\% de la población se localiza en áreas urbanas y que alrededor del $86 \%$ del PIB se produzca en esas áreas. Ello significa que el adecuado funcionamiento de los centros y sistemas urbanos es determinante en el proceso de desarrollo del país porque la necesidad de mantener tasas de crecimiento económico a un ritmo adecuado para la creación de riqueza en su conjunto, pasa por lo eficientes y funcionales que las aglomeraciones urbanas sean al proceso de producción de bienes y servicios. (INE_Chile, Instituto Nacional de Estadisticas, 2018; OCDE, Estudios Económicos de la OCDE, 2018)

En Chile la economía es abierta al mundo, opera por el libre mercado y el Estado ejerce un rol subsidiario. Un problema de alto riesgo es que la opacidad del mercado de suelos puede distorsionar gravemente el funcionamiento de las ciudades y la provisión de viviendas. Dado que el acceso al suelo urbano es función directa del ingreso, en una economía neoliberal el impacto residual del libre juego de la oferta y demanda ha sido la desigualdad en la distribución del ingreso (Índice Gini 44,4) y, entonces, la segregación de los grupos sociales en la ciudad es un impacto perceptible, incluso visualmente en la morfología urbana. Son fácilmente reconocibles los sectores de alto, medio y bajos ingresos en la ciudad. Chile ingresó a la OCDE como uno de los países más desiguales del mundo y sigue en esa posición con mejoras y deterioros según periodos. (OCDE, 2019; 2020)

El conocimiento del mercado de suelos es de crucial importancia para la toma de decisiones de los agentes privados en la gestión inmobiliaria y de los públicos para la orientación y regulación del desarrollo urbano. Más aún con la irrupción del capital financiero internacional, tradicional y no tradicional en el mercado. (Gasic, 2018)

La metodología es descriptiva-exploratoria-estadística utilizamos registros trimestrales de ofertas de suelo 1989-2018, y mediante análisis de correlaciones (Pearson, R; Spearman, Rho y Kendall, Tau_b) revisamos el comportamiento y asociación de las variables y buscamos regularidades. Para identificar tendencias realizamos proyecciones al año 2030 a través de previsiones con el modelo de HoltWinters para series temporales de suavizamiento exponencial por adaptarse fácilmente a cambios, tendencias y estacionalidad.

El articulo tiene dos objetivos, por una parte, contribuir al conocimiento del mercado de suelos en tanto variable esencial en el desarrollo de la ciudad y, por otra, difundir la información específica, la estructura, las regularidades y las tendencias para el Gran Concepción, en tanto un área urbana metropolitana típica de nivel intermedia y regional localizada 500 kilómetros al sur de la región capital chilena.

\subsection{Marco Teórico. Sobre el suelo urbano, la vivienda y el mercado}

En ese contexto y como el suelo urbano es un factor de producción escaso y clave por ser el soporte a todas las actividades urbanas, el estudio del mercado en que se transa se torna esencial y constituye uno de los aspectos del mayor interés tanto para los agentes privados vinculados a la inversión inmobiliaria buscando una adecuada tasa de ganancia, como para los planificadores en el sector público buscando maximizar el bien común, entendido como habitabilidad, en el ámbito urbano. (Sabatini, 1990; Daher, 1991; Gaete-Feres, 2003; Trivelli, 2010; Abramo, 2012; Harvey, 2018; Jojoa Villarraga \& Marmolejo Duarte, 2013)

El esfuerzo por incorporar regulaciones al mercado de suelos ha sido un desafío importante en la disciplina, particularmente para alcanzar mayor seguridad en los registros y transacciones,

ACE, 16 (4.6) CC BY-ND 3.0 ES | UPC Barcelona, España | Tendencias del mercado de suelo urbano en periodo

largo. Concepción, Chile. 1989-2018. DOI: http://dx.doi.org/10.5821/ace.16.46.9946 
transparencia del mercado y recuperación de plusvalías. (Furtado, 1997; M. Smolka \& Amborski, 2003); (Morales Schechinger, 2005; (Jaramillo, 2009; Vejarano, 2008; Alcazar Molina, 2008; Theodore, Peck, \& Brenner, 2009; Smolka, 2012; Arellano \& Roca, 2013; Lincoln Institute, 2018; Vergara-Perucich \& Aguirre-Núñez, 2020). En Chile para fortalecer la trasparencia del mercado y recuperar alguna parte de las plusvalías generadas sobre el suelo privado por la acción pública, se aprobó a principios de 2018 la ley 21.078 que incorpora adicionalmente un impuesto del 10\% sobre el aumento de valor en las transacciones de predios derivados de la ampliación del límite urbano. (MINVU_Chile, 2018).

Especial preocupación presenta la investigación en la relación vivienda y mercados de suelo mostrando esencialmente los fenómenos de acceso a la vivienda como un asunto fundamental, a su vez, de acceso al suelo (Clichevsky, 2003); MINVU_Chile, 2004); (Baer, 2008). También como un fenómeno de pobreza, segregación y exclusión social derivada del precio y la dinámica del mercado de suelos (Ziccardi, 2008); (SABATINI \& BRAIN, 2008); (Winchester, 2008); (Viloria, 2011); (Sabatini, 2016); que afecta también seriamente el derecho a la vivienda (Gledhill, 2010); (Rolnik \& Dapena, 2014); por cierto en la vivienda social (Trivelli, 2010); (Calderón, 2015); como también la relación entre precios de la vivienda y del suelo (Gómez Riocerezo, 2012); o la carencia de vivienda explicada por el funcionamiento del mercado inmobiliario (García Pérez, 2014); (Moreno, 2014). Finalmente, se discuten elementos de política de vivienda y su estrecha relación con el urbanismo (Vinuesa Angulo, Riva Ámez, \& Palacios García, 2009); o como explicación de las tendencias de crecimiento urbano (de Mattos, Fuentes, \& Link, 2014). La segregación y exclusión preocupa también al propio gobierno nacional el que en enero de 2018 envió al Congreso Nacional un proyecto de ley de integración social y urbana, ingresado a la Cámara de Diputados por el boletín №12288-14. (Gobierno_Chile, 2018)

En síntesis, los estudios anteriores concluyen en que el asunto del acceso a la vivienda es un problema esencial de acceso al suelo y ello, por cierto, resulta mucho más evidente en una economía neoliberal con mercado abierto en que el acceso al suelo es función directa del ingreso económico. Por lo mismo, el estudio de los mercados de suelo resulta determinante también para el diseño de políticas públicas buscando avanzar en la provisión de viviendas y para la habitabilidad en los asentamientos humanos, es decir, para la calidad de vida. Dicha dinámica es compleja, altamente integrada e interdependiente y se esquematiza en la figura 1.

\section{Figura 1. Dinámica de la Economía-Mercado-Suelo-Desigualdad-Segregación}

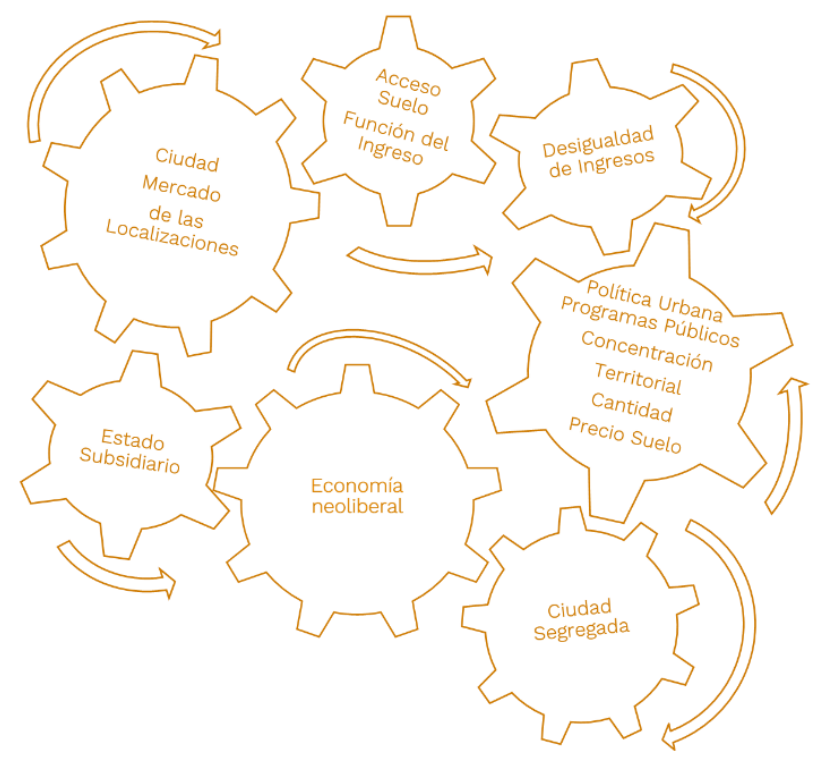

Fuente. Elaboración propia.

ACE, 16 (4.6) CC BY-ND 3.0 ES | UPC Barcelona, España | Tendencias del mercado de suelo urbano en periodo

largo. Concepción, Chile. 1989-2018. DOI: http://dx.doi.org/10.5821/ace.16.46.9946 


\subsection{Sobre el área territorial de estudio}

Chile está organizado administrativamente en 16 regiones, 54 provincias y 346 comunas. El territorio se estructura en torno a tres grandes áreas metropolitanas de concentración poblacional urbana: el Gran Santiago, ciudad capital (40,6\%); el Gran Valparaíso (6,1\%) y el Gran Concepción (6,3\%); las que juntas $(53,0 \%)$ corresponden al total de la población nacional urbana metropolizada. (Población Urbana no Metropolizada: 34,8\%; Rural: 12,2\%). (Instituto Nacional de Estadisticas INE_Chile, 2018) Por su parte, el Gran Concepción está ubicado entre los paralelos 36012' y 37015' de latitud sur y entre los grados 7312' y 7240' de longitud oeste; a 500 Km al sur de Santiago, capital del país; en la Región del Biobío, la cual debe su nombre a que lo cruza el río Biobío, el más ancho del país y de importancia histórica destacada por cuanto fue, hasta mediados del siglo XVIII, la frontera natural entre Chile y la nación indígena mapuche. Es un área de alta concentración poblacional, de servicios, educacional, científica, e industrial; de importancia en el desarrollo regional y nacional. Constituye también un área territorial y de planificación urbana claramente definida en los distintos instrumentos de planificación y programación vigentes.

La Región se localiza en la zona centro sur del país entre los 3626' y los 38029' de latitud sur, se estructura en 3 provincias y 33 comunas $^{1}$. La población regional al último censo (2017) es de 1.556.805 habitantes, con el $88,6 \%$ urbana (país 87,8\%). Respecto al país, la región abarca el 3,2\% del territorio continental y concentra cerca del 8,86\% de la población (tercera después de la Región Metropolitana de Santiago, Región Capital y de la de Valparaíso), con una densidad poblacional superior a la nacional de 65,17 Hab/ $/ \mathrm{Km}^{2}$, (país: 8,77 Hab/ $/ \mathrm{Km}^{2}$ ) y una tasa de crecimiento intercensal 2002-2017 inferior a la nacional de $-16,3 \%^{2}$. (País: 1,0\%). El grueso de su producción (75\%) es intensiva en recursos naturales, proviene de los sectores forestal y pesquero, se orienta al mercado internacional y los principales productos son: rollizos de madera, pino radiata y harina de pescado. La Provincia de Concepción se divide en 12 comunas, tiene una superficie de 3.439,0 km² (14,40 \% de la Región); una población total de 995.658 habitantes (64,00\% de la Región), con un 97,00\% habitando en áreas urbanas y una densidad poblacional de 291,20 Hab/ $\mathrm{Km}^{2}$, muy superior a la regional (65,01 Hab/Km2). (Figura 2)

Figura 2. Región del Biobío, Provincias y Gran Concepción
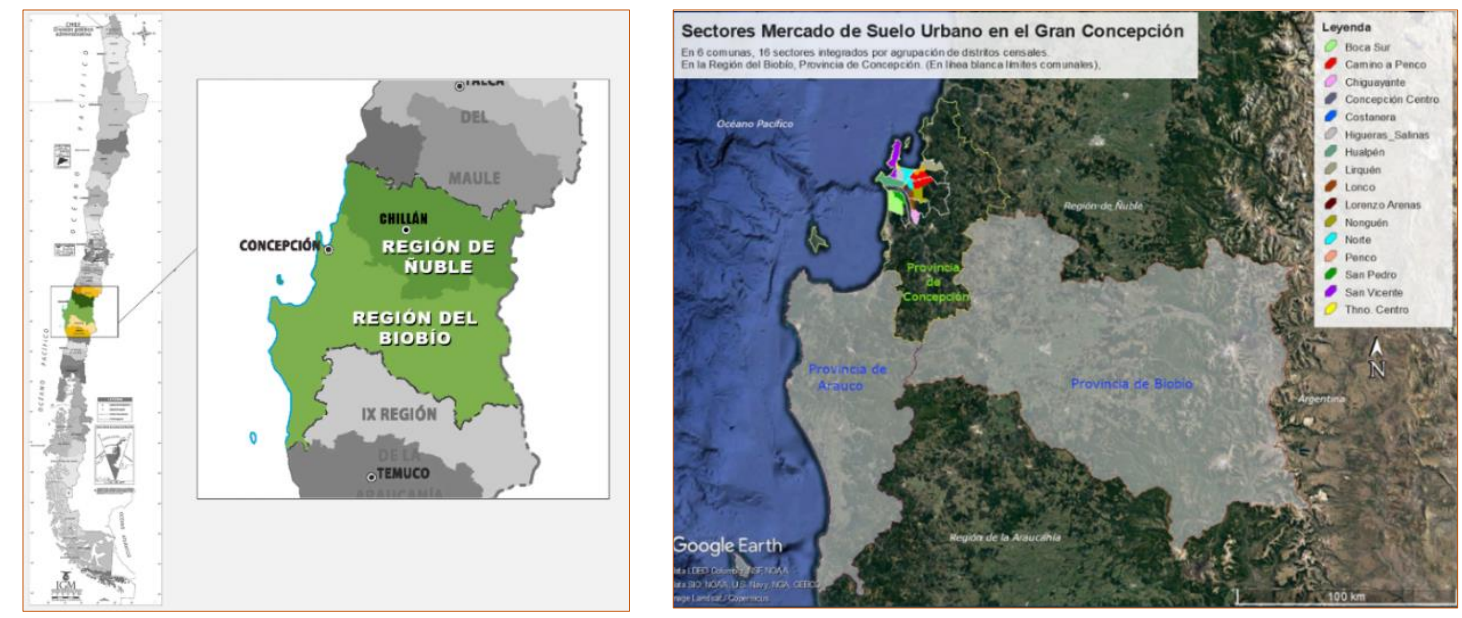

Fuente: Plano ubicación nueva Región del Biobío, Instituto Geográfico Militar (2018). Ubicación de sectores en provincia y región. Elaboración propia con datos INE, Censo 2017 y Boletín MSU-UBB 2 Trimestre 2018.

\footnotetext{
${ }^{1}$ El 05 de septiembre de 2017, fue publicada en el Diario Oficial la Ley N²1.033, que crea la XVI región de Ñuble y las provincias de Diguillín, Punilla e Itata. Entró en vigencia el 06 de septiembre de 2018. Su territorio comprende la anterior provincia de Nuble integrante del territorio de la región del Biobío.

${ }^{2}$ Derivado de la creación de la región de Ñuble.
}

ACE, 16 (4.6) CC BY-ND 3.0 ES | UPC Barcelona, España | Tendencias del mercado de suelo urbano en periodo

largo. Concepción, Chile. 1989-2018. DOI: http://dx.doi.org/10.5821/ace.16.46.9946 
Esta unidad urbana metropolitana se desarrolla en el borde del océano pacífico en un eje litoral de unos $31 \mathrm{~km}$ sobre los espacios litorales que se estrechan entre la Cordillera de la Costa y la línea costera de la provincia de Concepción. Está formado por unidades funcional y socialmente especializadas que se separan sobre el espacio a distancias límite. La ciudad de Concepción, donde se realizan todas las operaciones públicas y privadas que interesan al conjunto urbano y a la región, ejerce el rol de centro principal de servicios. A corta distancia $(15 \mathrm{~km})$, físicamente integrado a Concepción, se desarrolla el complejo portuario industrial (siderurgia, petróleo) de Talcahuano y San Vicente; Penco y Lirquén, centros tradicionales de la loza y el vidrio, se establecen cada vez más vinculados al centro direccional en condición de áreas residenciales; Chiguayante (12 Km), antiguo centro textil y San Pedro $(7 \mathrm{Km})$, constituyen esencialmente áreas de expansión residencial de Concepción. (Párrafo actualizado y basado parcialmente en Hernandez, 1983)

Al interior de la unidad urbana descrita, se verifica el funcionamiento de un mercado inmobiliario consolidado, vigoroso y dinámico a la luz de la cantidad de agentes que participan y del permanente volumen de ofertas. Por lo mismo, resulta de alto interés concentrar esfuerzos en la investigación vinculada al tema, con el fin de aportar antecedentes y análisis para apoyar y perfeccionar la gestión urbana tanto del sector público como del privado, así como contribuir a la transparencia mediante la difusión de conocimiento validado.

El área de estudio es la segunda en tamaño y relevancia en el país. Constituye una unidad urbana altamente integrada lo que se verifica por la interdependencia entre unidades administrativas sub territoriales (comunas, sectores y barrios) con roles funcionales y usos predominantes en lo general: residencial, servicios educacionales y administrativos, industria manufacturera no contaminante, industria pesada siderúrgica, petrolera y pesquera. Lidera el sistema urbano la ciudad de Concepción, capital de la región y la provincia. La secunda la comuna y ciudad de Talcahuano que concentra las industria pesada y amplios barrios residenciales. Penco y Liquen de tamaños residenciales menores; pero concentran importante infraestructura portuaria esenciales para el rol exportador del territorio regional y sur del país. Las restantes unidades urbanas son esencialmente residenciales y desempeñan roles manufactureros de tamaño variable.

Por otra parte, una de las características de esta aglomeración urbana es el conjunto de condicionantes y restricciones que generan tanto el espacio físico natural como el espacio físico adaptado que la soporta y que se traducen en escasez de suelo urbano para su desarrollo futuro. Los indicadores de consumo de suelo muestran que en una década las seis comunas en estudio se expandieron en 882,93 ha, un 9,31\%. Destacan las expansiones de San Pedro de la Paz en 379,33 has (28,1\%) y Hualpén en 105,16 has (9,84\%). Las demás comunas estuvieron por debajo del promedio. (Cálculos propios a partir de datos en)(Laboratorio Biociudades Minvu_Seremi Biobío, 2018).

\subsection{Metodología}

Para la investigación se utilizó la información proveniente de los boletines "Mercado de Suelo Urbano en el Gran Concepción (MSU), que edita trimestralmente desde 1989 a la fecha el Departamento de Planificación y Diseño Urbano de la Facultad de Arquitectura, Construcción y Diseño, en la Universidad del Bío-Bío (UBB) y cuyo origen de los datos es la sección de Avisos Económicos del Diario "EL SUR", versión papel y digital, principal periódico local de Concepción, para los días domingo. El conjunto de avisos publicados en el diario puede ser considerado como una muestra, ya que no todos los oferentes publican su oferta; pero representativa porque su volumen es considerable y persistente y el diario constituye referencia obligada para evaluar la expectativa de precio incluso para el oferente que no publica avisos.

ACE, 16 (4.6) CC BY-ND 3.0 ES | UPC Barcelona, España | Tendencias del mercado de suelo urbano en periodo

largo. Concepción, Chile. 1989-2018. DOI: http://dx.doi.org/10.5821/ace.16.46.9946 
El Gran Concepción, para efectos del registro de datos del mercado de ofertas de suelo urbano, está integrado por seis comunas: Concepción, Talcahuano, Hualpén, San Pedro de la Paz, Chiguayante y Penco (Figura 3) que abarcan una superficie de 659,0 km² (1,8\% del territorio regional y 19,20\% de la Provincia). Con una población total de 710.441 habitantes que representan el 36,15\% del total regional y el $73,4 \%$ de la provincia. La población urbana alcanza prácticamente al $100 \%$ con una densidad poblacional de 1.078,06 $\mathrm{Hab} / \mathrm{Km}^{2}$, superior a la regional y provincial.

Figura 3. Gran Concepción: 16 sectores para el registro de ofertas de suelo urbano

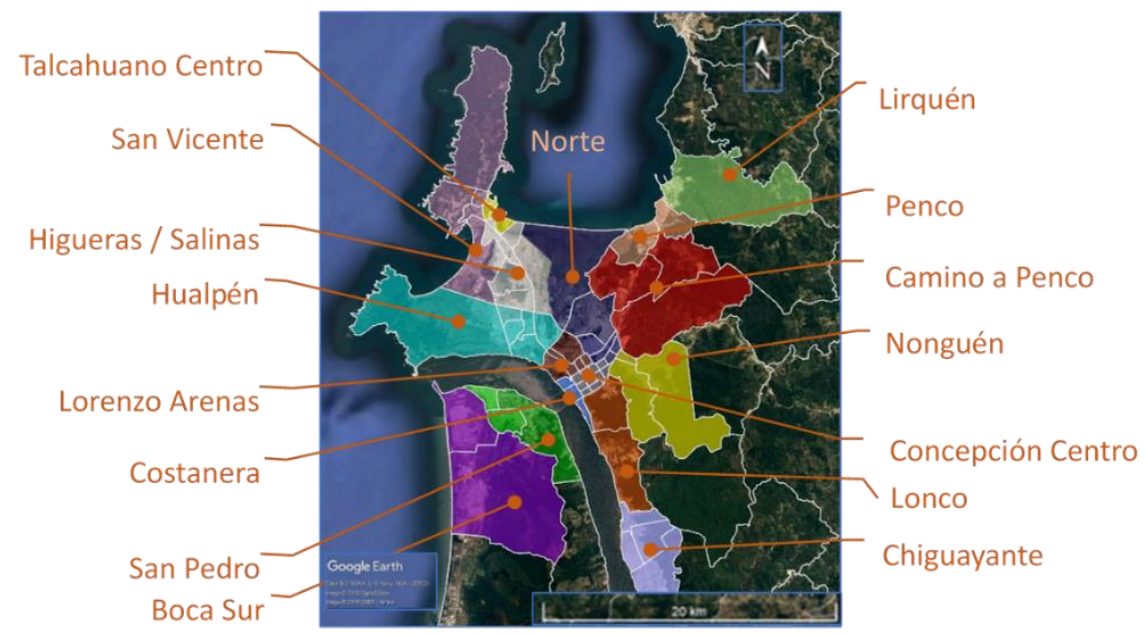

Fuente: elaboración propia, base Boletín MSU/UBB, №115; 2으 Trim 2018; pp.4 y distritos censales Censo 2017.

Comprende, dentro de las comunas mencionadas, siete asentamientos urbanos: Concepción, San Pedro, Chiguayante, Talcahuano, Hualpén, Penco y Lirquén; sectorizados para efectos del registro de ofertas del mercado de suelo urbano de acuerdo a la agrupación y localización de distritos censales vigentes indicada en la Tabla 1.

Tabla 1. Gran Concepción: comunas, sectores MSU y distritos censales

\begin{tabular}{|c|c|c|}
\hline Comuna & Sector & $\begin{array}{l}\text { № Distrito Censal Vigente Urbano } \\
\text { (INE 2017) }\end{array}$ \\
\hline \multirow{6}{*}{ CONCEPCIÓN } & Centro & $1-2-3-4-6-12-13-20-21-22$ \\
\hline & Norte & $14 b\left(^{\star}\right)-15-16-17-18-19$ \\
\hline & Lorenzo Arenas & $7-8-9-10-11-14$ \\
\hline & Costanera & $5-26-27$ \\
\hline & Camino a Penco & $28-5-6$ \\
\hline & Nonguén & $23-25-32$ \\
\hline \multirow{2}{*}{ SAN PEDRO } & San Pedro & $1-3-4$ \\
\hline & Boca Sur & 2 - 5 (incluye áreas urbanas de Lagunillas y Lomas Coloradas) \\
\hline \multirow{2}{*}{ CHIGUAYANTE } & Chiguayante & $2-3-4-5$ \\
\hline & Lonco & 1 - 24 (de comuna de Concepción) \\
\hline \multirow{2}{*}{ PENCO } & Penco & $1-2$ \\
\hline & Lirquén & 3. \\
\hline \multirow{3}{*}{ TALCAHUANO } & Talcahuano Centro & $1-2-3-4$ \\
\hline & San Vicente & $5-8-10 b(*)-16$ \\
\hline & Higueras / Las Salinas & $9-10 a\left(^{*}\right)-11-12-13-14 a\left(^{*}\right)-15 .-16-17$ \\
\hline HUALPÉN & Hualpén & $1-2-3-4-5-6$ \\
\hline
\end{tabular}

(*) Debido a su excesiva extensión y características, el distrito 14 se dividió en dos: "14a" desde Autopista Concepción-Talcahuano hasta canal Ifarle se integra al Sector Higueras /Salinas. El "14b" se integra al sector Concepción Norte Distrito 16. Fuente: Boletín MSU/UBB, № 115; 2은 Trimestre 2018; pp.4.

ACE, 16 (4.6) CC BY-ND 3.0 ES | UPC Barcelona, España | Tendencias del mercado de suelo urbano en periodo

largo. Concepción, Chile. 1989-2018. DOI: http://dx.doi.org/10.5821/ace.16.46.9946 
En el artículo examinamos el comportamiento que presenta la oferta de suelo urbano, en el área de estudio, a través del análisis y evolución de los precios, de la cantidad y de la superficie a escala global y por sectores; para detectar las regularidades, tendencias y variaciones, basándose en la información proveniente del registro sistemático de las ofertas publicadas ininterrumpidamente durante veintisiete años desde el cuarto trimestre del año 1989 al cuarto trimestre del año 2018 -

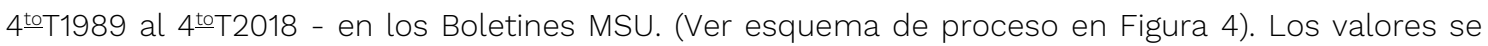
indica en Unidad de Fomento (UF), unidad de cuenta monetaria establecida por el Gobierno de Chile, que se va reajustando diariamente por el índice de Precios al Consumidor (IPC) del mes anterior (código ISO 4217:2015, N990). La UF se creó, por Decreto № 40 del 2 de enero de 1967 del Ministerio de Hacienda, para expresar los montos adeudados por concepto de créditos para la vivienda; pero su uso se generalizó a otro tipo de deudas, así como a instrumentos de ahorro y depósitos y otras transacciones. A la fecha de este artículo, 11-12-2020, el valor de una UF es el siguiente: $\$ C h=29.089,10 ; € E \cup R=32,51 ;$ \$US= 39,41.

Figura 4. Esquema de proceso
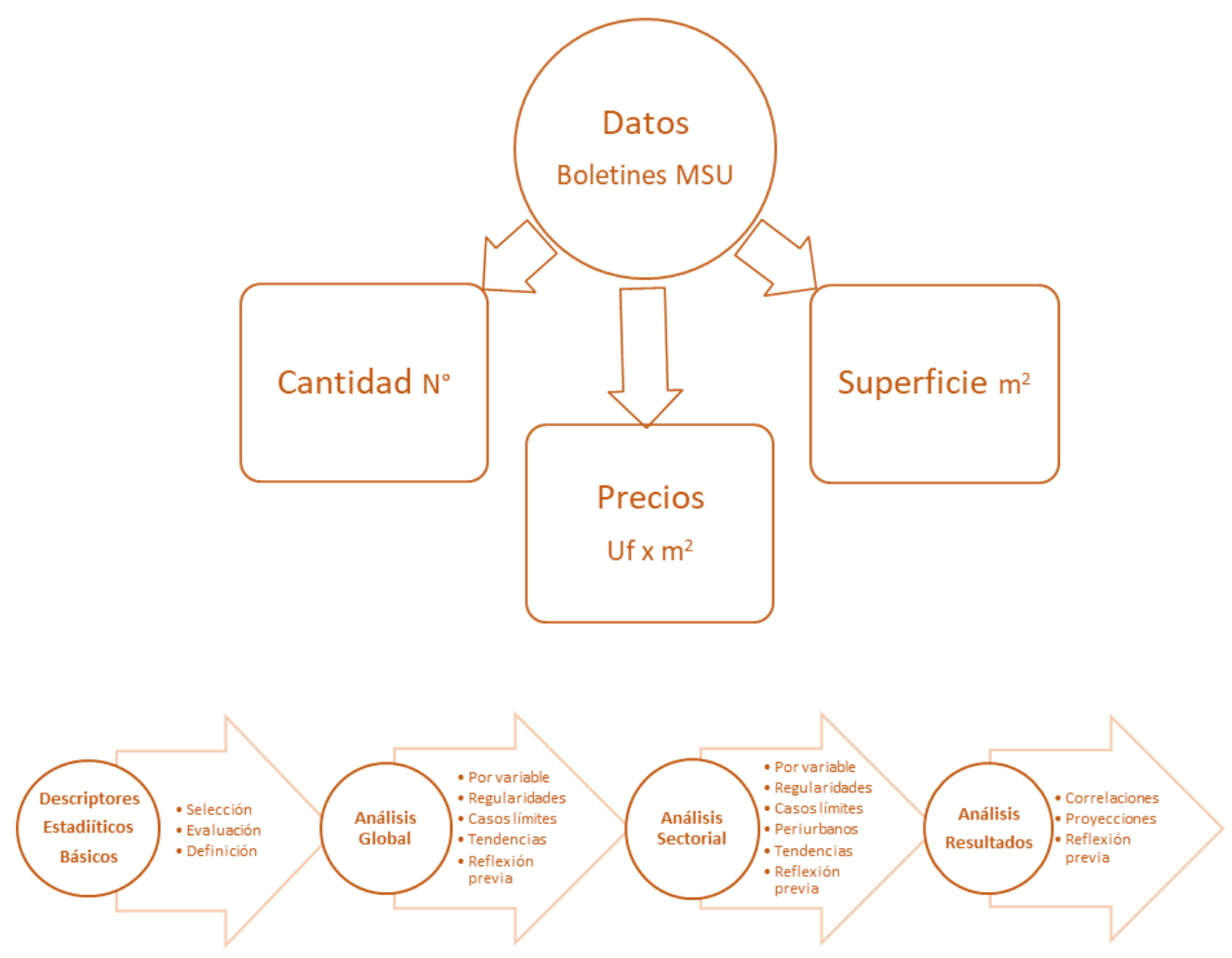

Fuente. Elaboración propia.

Para evitar distorsiones de los resultados, en los cálculos estadísticos no se consideraron aquellos trimestres sin registro de ofertas en el sector correspondiente. Para visualizar mejor las fluctuaciones, a la gráfica pertinente se le incorporó una línea de tendencia mediante una curva polinómica, de orden seis, para poder detectar y apreciar adecuadamente el comportamiento entre períodos con sus ciclos de alza y baja. La línea de tendencia polinómica es una de las alternativas de suavización funcional y el grado 6 se decidió por absorber mejor las variaciones parciales y la necesidad de representar las grandes fluctuaciones de valores en periodos amplios como es el caso. Por cierto, su confiabilidad es relativa a la regularidad de los datos y a la representación buscada. Como verificador se utilizó coeficiente de determinación $\mathrm{R}^{2} \mathrm{y}$, para las variables involucradas, luego de revisar varias alternativas, la seleccionada resultó ser la de mayor expresión tendencial.

ACE, 16 (4.6) CC BY-ND 3.0 ES | UPC Barcelona, España | Tendencias del mercado de suelo urbano en periodo

largo. Concepción, Chile. 1989-2018. DOI: http://dx.doi.org/10.5821/ace.16.46.9946 
Luego se efectuó un análisis de correlaciones (Pearson, R; Spearman, Rho y Kendall, Tau_b) entre las variables de registro (cantidad, superficie y precio) y para los conjuntos de datos correspondientes; revisamos el comportamiento y asociación de las variables y buscamos, regularidades. Al respecto debe tenerse presente que un alto grado de asociación no implica inferir automáticamente relación causal entre las variables. Para tendencias realizamos proyecciones al año 2030 a través de previsiones con el modelo de Holt-Winters para series temporales de suavizamiento exponencial por adaptarse fácilmente a cambios, tendencias y estacionalidad. Evidentemente, las hipótesis que se plantean más adelante, en cada caso, tienen el carácter de preliminares y pueden ser modificadas incorporando otros estudios y consideraciones. Adicionalmente y para contrastar el comportamiento del mercado de suelo urbano (cantidad, superficie y precio) en relación con el desempeño de la economía regional se utilizó el Índice de Actividad Económica Regional (INACER) que elabora el Instituto Nacional de Estadísticas, para la región del Biobío.

\section{Resultados}

\subsection{Resultados Globales de la oferta de suelo urbano en el Gran Concepción}

En el Gran Concepción la oferta de suelo ha tenido constantes variaciones expresadas en expansión y contracción según períodos, aunque en términos lineales, entre el cuarto trimestre de 1989 e igual trimestre del año 2018, el número de ofertas se redujo en un 93,75\%, la superficie ofrecida lo hizo en un 97,93\%; pero el precio se incrementó en un 253,21\% sobre el valor de la Unidad de Fomento (UF). En el periodo, la cantidad de ofertas promedio fue de 210 , la superficie promedio ofrecida fue de 91,00 ha y el precio promedio ponderado fue de 2,9744 UF $\times \mathrm{m}^{2}$. Los valores promedios ponderados trimestrales del período analizado, 4느T1989 al 4느T2018, se presentan en la Figura 5.

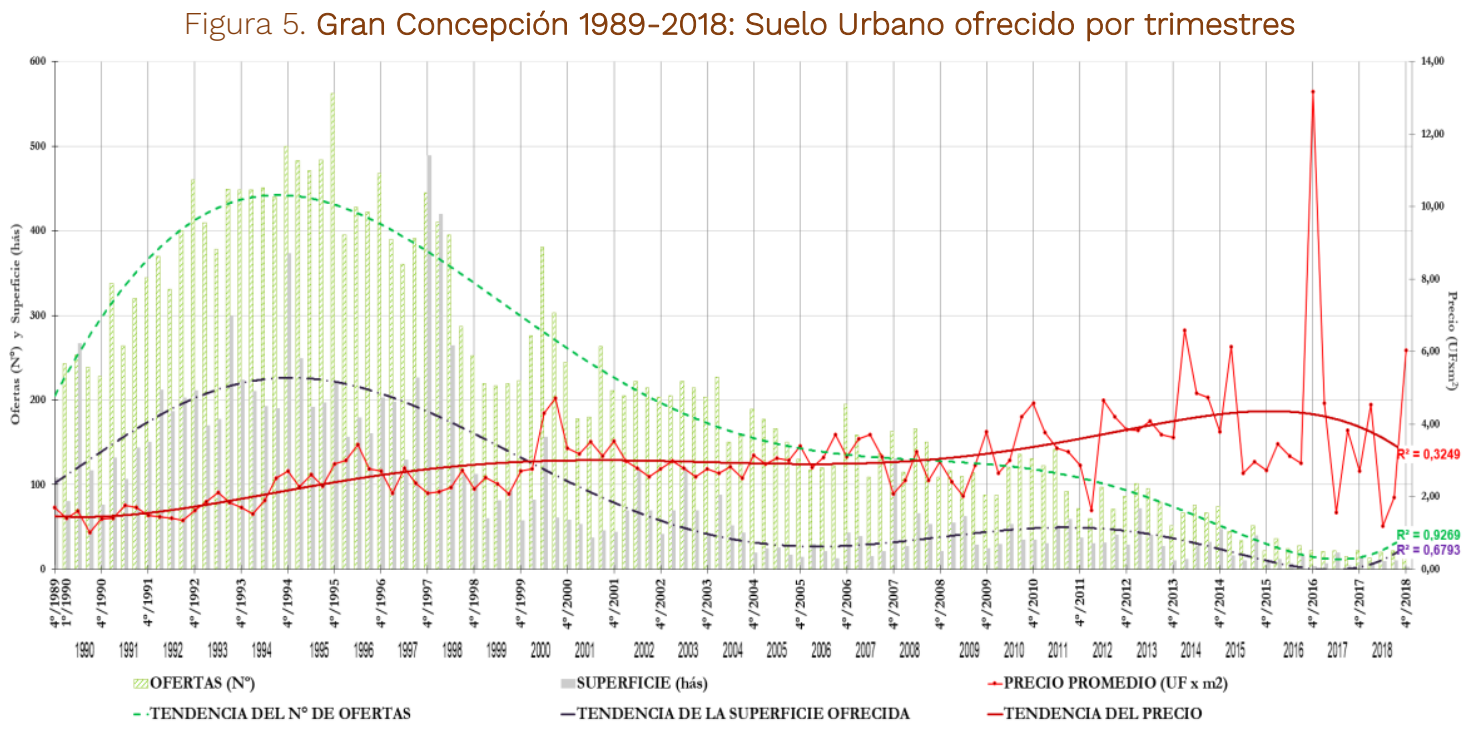

Fuente: Elaboración propia, con datos Boletines MSU-UBB. Para claridad del gráfico se etiquetó sólo el cuarto trimestre de cada año excepto en 1990, luego del trimestre inicial en 1989.

En función de los datos del registro de las variables presentadas en la Figura 5, se indica a continuación el comportamiento de cada una de ellas.

ACE, 16 (4.6) CC BY-ND 3.0 ES | UPC Barcelona, España | Tendencias del mercado de suelo urbano en periodo

largo. Concepción, Chile. 1989-2018. DOI: http://dx.doi.org/10.5821/ace.16.46.9946 


\subsubsection{Número de ofertas y tendencia}

Esta variable se mantuvo en una banda acotada por un valor mínimo de 13 ofertas el 1erT2018 y un máximo de 562 ofertas el 4toT1995, con un promedio de 210, mediana de 180, moda de 22 y desviación estándar de 144. El número de ofertas se redujo en un 93,75\% entre el 4ํㅜ1989 y 4toT2018. Los datos presentaron moderada estabilidad a juzgar por su dispersión respecto del promedio; pero con una fuerte caída en 1998 y con tendencia a la baja desde entonces.

\subsubsection{Superficie ofrecida y tendencia}

La superficie fluctuó en una banda acotada por un valor mínimo de 2,24 ha el 4ํㅜ2018 y un máximo de 488,43 ha. el 4toT1997, con un promedio de 90,55 ha, mediana de 53,37 ha, moda 69,21 y desviación estándar de 91,64 ha. respecto al promedio. La superficie ofrecida presentó alta inestabilidad a juzgar por su dispersión y disminuyó en un 97,93\% entre el 4ํㅜ1989 y 4ํㅡT2018. La mayor inestabilidad se produce entre $2 \underline{\text { do }} T 1997$ y 2은 2000 . La caída se inició en 1998 y continuó la tendencia a la baja desde ese año.

\subsubsection{Precio promedio y tendencia}

El precio se movió en una banda acotada por un valor mínimo de 1,01 Unidades de Fomento el metro cuadrado (UFxm²) el 3erT1990 y un máximo de 13,1700 UFxm² el 4to T2016, con un promedio de 2,9744 UFxm², mediana de 2,7902 UFxm² y desviación estándar de 1,3993 UFxm² respecto al promedio. Como se verifica en la Figura 5, los precios dentro de la banda indicada presentaron cierta estabilidad a juzgar por su dispersión; con largos ciclos de alza y baja, aunque en todo el período se observa tendencia sostenida al alza y con un incremento del 253,21\% en el período.

Es importante observar la tendencia a la baja del número de ofertas y de la superficie ofrecida desde 1998 en adelante en relación con la tendencia sostenida al alza del precio en igual período. La desindexación definitiva entre ambas variables ( $N^{\circ}$ de ofertas y superficie) y el precio se produce

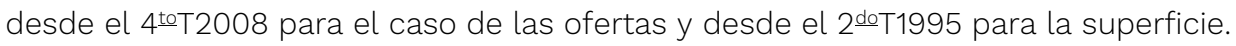

Por otra parte, y aunque influyen casos específicos, como fue una oferta de un terreno de $154 \mathrm{Ha}$. en junio de 1990, se pueden observar tendencias cíclicas por estacionalidad en el precio de oferta, por cuanto se detecta cierta depresión en verano (1 1 er trimestre) y en invierno (3er trimestre), posiblemente debido a la concentración en ciclos trimestrales de las transacciones efectivamente realizadas en el mercado.

Durante el primer trimestre del año 2010, en la madrugada del 27 de febrero a las 03:34:17 hora local, se produjo un fuerte sismo con tsunami de intensidad 8, 8 Richter, uno de los cinco terremotos más fuertes del mundo registrados desde el año 1900. El epicentro se ubicó en el Mar Chileno, frente a la localidad de Cobquecura en la Región del Bío-Bío, a unos 150 kilómetros al nor-oeste de Concepción. Toda el área territorial que aborda este estudio sufrió importantes impactos. Desde el segundo trimestre del mismo año hasta el cuarto del 2012 el mercado inmobiliario de ofertas de suelo se mostró con variaciones en todos los indicadores en estudio para posteriormente retomar su dinámica.

Una primera reflexión del comportamiento global del mercado en el área de estudio es que este presenta flexibilidades observables por periodo; pero en un marco acotado por bandas de valores que tienden al alza respecto del precio y a la baja en cantidad y superficie. Es decir, en mercados abiertos de corte liberal o neoliberal los precios fluctúan, en lo general, en función de las fuerzas de oferta y demanda y no necesariamente en virtud de las políticas de desarrollo urbano.

ACE, 16 (4.6) CC BY-ND 3.0 ES | UPC Barcelona, España | Tendencias del mercado de suelo urbano en periodo

largo. Concepción, Chile. 1989-2018. DOI: http://dx.doi.org/10.5821/ace.16.46.9946 
Por su parte, los impactos derivados de desastres alteran fuertemente el comportamiento de dichas bandas de precio.

\subsubsection{Mercado del Suelo Urbano y Economía Regional}

Para contrastar el comportamiento de las variables de registro del mercado de suelo urbano (cantidad, superficie y precio) en relación con el desempeño de la economía regional se utilizó el Índice de Actividad Económica Regional (INACER) para la Región del Biobío, que entrega el Instituto Nacional de Estadísticas (INE) desde el año 1996. Se expresaron todos los datos en la forma de series índices de base 100. (Instituto Nacional de Estadísticas INE_Chile, 2019, INACER).

El resultado muestra que la dinámica de crecimiento de los precios, aunque hubo importante sincronización, en algunos periodos se desacopló de la dinámica de crecimiento de la economía regional (entre el primer trimestre de 1996 y el segundo de 2003; y entre el primero de 2010 y el segundo de 2016), para posteriormente volver a acoplarse. Ello debido a ciclos propios de la actividad económica en un mercado abierto altamente sensible a las fluctuaciones de la economía externa; pero también a impactos locales como el incendio en el sector San Vicente en 1993, las inundaciones en 2006 y el terremoto de 2010. Por su parte, el número de ofertas y la superficie tuvieron un comportamiento inverso al desempeño de la economía. (Figura 6)

Figura 6. Gran Concepción 1989-2018: Suelo urbano y economía. Índices de ofertas, superficies, precios y actividad económica

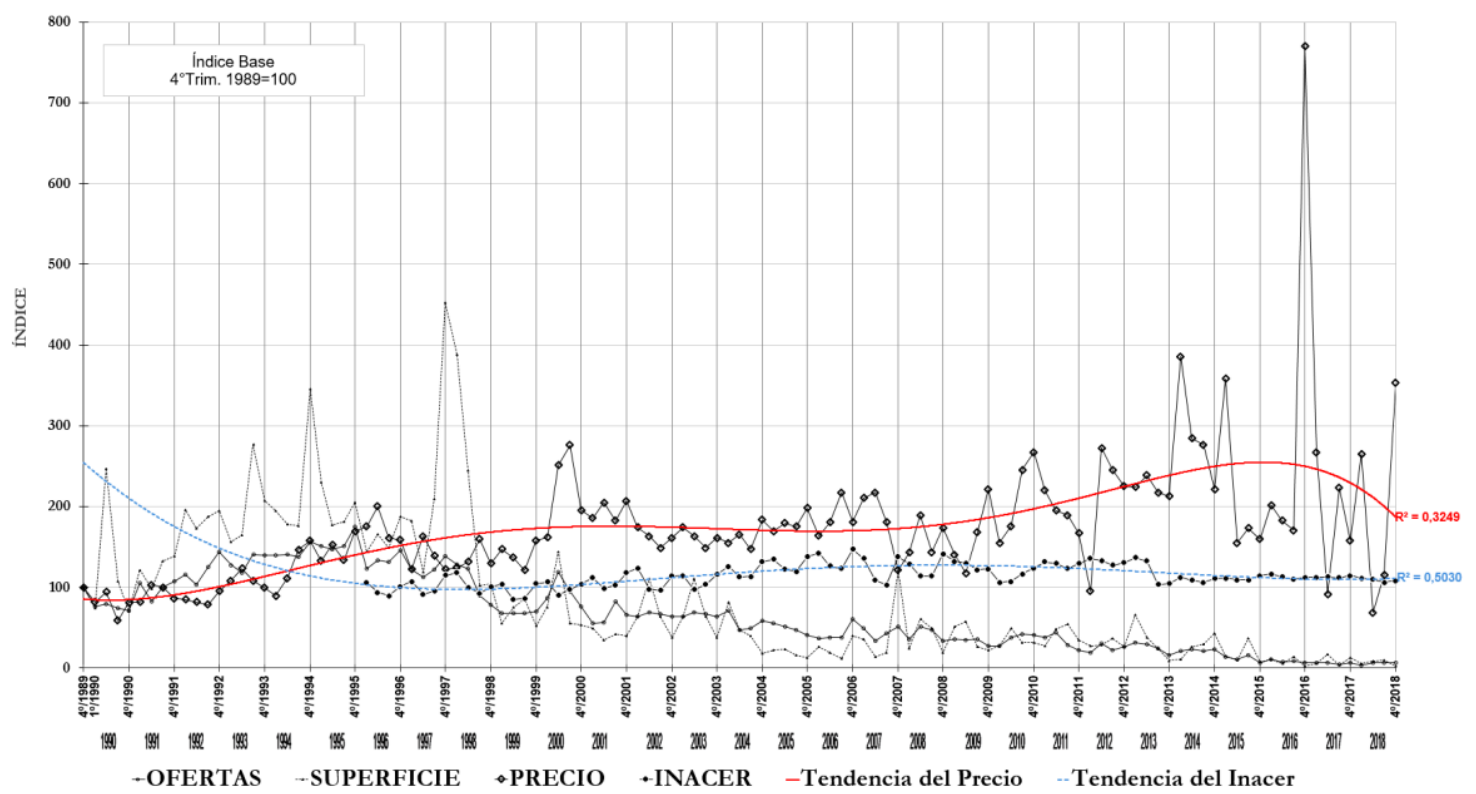

Fuente: Elaboración propia, con datos Boletines MSU-UBB. INACER, INE Biobío.

\subsubsection{Correlaciones}

Como se indica en la Tabla 2, el cálculo de los coeficientes de correlación (Pearson, R; Spearman, Rho y Kendall, Tau_b) nos muestra que las asociaciones entre variables son significativas y del mismo orden de magnitud con los tres indicadores lo que implica robustez del análisis tanto para las correlaciones positivas como negativas.

ACE, 16 (4.6) CC BY-ND 3.0 ES | UPC Barcelona, España | Tendencias del mercado de suelo urbano en periodo

largo. Concepción, Chile. 1989-2018. DOI: http://dx.doi.org/10.5821/ace.16.46.9946 
Tabla 2. Coeficientes de Correlación

orrelaciones de Pearson

\begin{tabular}{|c|c|c|c|c|}
\hline & & & \multirow[b]{2}{*}{ Precio_UFxm2 } \\
\hline & & Ofertas_№ & Superficie_ha & \\
\hline \multirow{3}{*}{ Ofertas_№ } & Correlación de Pearson & 1 &, $854^{* *}$ &,$- 420^{* *}$ \\
\hline & Sig. (bilateral) & &, 000 &, 000 \\
\hline & $N$ & 117 & 117 & 117 \\
\hline \multirow{3}{*}{ Superficie_ha } & Correlación de Pearson & $854^{\star \star}$ & 1 &,$- 400^{\star *}$ \\
\hline & Sig. (bilateral) &, 000 & &, 000 \\
\hline & N & 117 & 117 & 117 \\
\hline \multirow{3}{*}{ Precio_UFxm2 } & Correlación de Pearson &,$- 420^{\star *}$ &,$- 400^{* *}$ & 1 \\
\hline & Sig. (bilateral) &, 000 &, 000 & \\
\hline & $N$ & 117 & 117 & 117 \\
\hline
\end{tabular}

**. La correlación es significativa al nivel 0,01 (bilateral).

Correlaciones de Kendall y Spearman

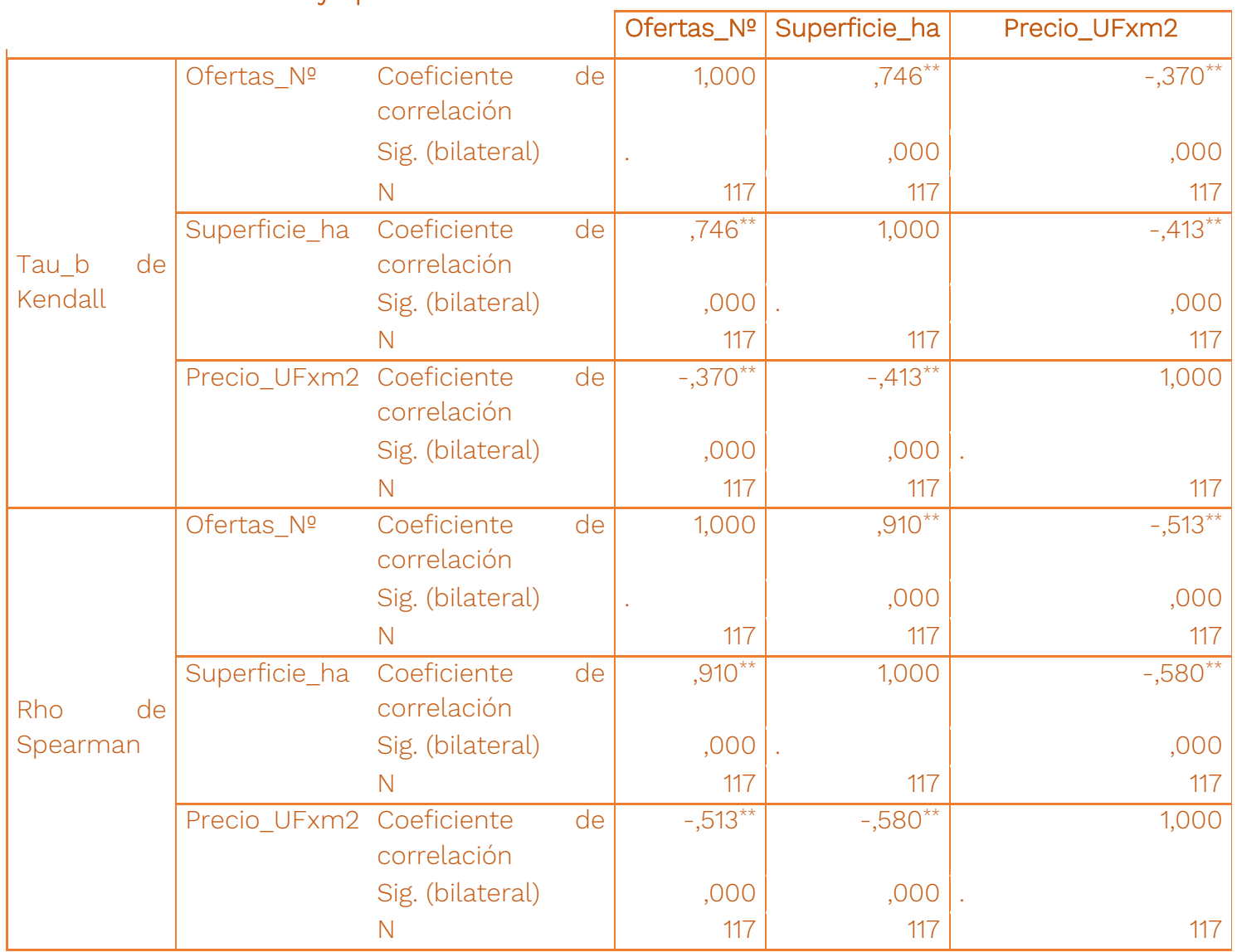

**. La correlación es significativa al nivel 0,01 (bilateral).

Fuente: Elaboración propia a partir de datos Boletines MSU/UBB. 
La cantidad de ofertas y la superficie ofrecida presentaron fuerte grado de asociación positiva tendiendo a aumentar la una con el aumento de la otra: $R=0,854 ;$ Tau_b=0,746 y Rho=0,901. El precio también se asoció, aunque en forma menos significativa; pero alta y en relación inversa tanto con el número de ofertas como con la superficie ofrecida, disminuyendo al aumentar aquellas. En particular, el precio con el número de ofertas arrojó un $\mathrm{R}=-0,420$; un Tau_b=-0,370 y un Rho=-0,513; y con la superficie ofrecida un $\mathrm{R}=-0,400 ;$ Tau_b=-0,413 y un Rho=-0,580.

\subsection{Resultados por sectores de la oferta de suelo urbano en el Gran Concepción}

\subsubsection{Respecto de los Precios Promedio}

El análisis de los precios promedio por trimestre, ponderados por la superficie, y del promedio general del período estudiado (Tabla 3) presenta notables regularidades, lo que indica la existencia de una cierta estructura de sectores al interior del Gran Concepción, de relativa estabilidad, con algunos que actúan de marco para la oferta general - el precio menor y mayor - Lirquén y Concepción Centro, con una alta variación (de 0,0134 UF x $m^{2}$ a 10,4780 UF x m²) lo que evidencia la amplitud y dinámica del mercado.

Tabla 3. Gran Concepción 1989-2018: suelo urbano ofrecido por sectores. Promedio trimestral

\begin{tabular}{|c|c|c|c|c|c|}
\hline \multirow[t]{2}{*}{ Sectores } & Numero & Ofertas & Superficie & & Precio prom \\
\hline & Cantidad & $\%$ & Total $\left(\mathrm{m}^{2}\right)$ & $\%$ & $\mathrm{UF} \times \mathrm{m}^{2}$ \\
\hline Concepción Centro & 30 & 13,64 & $31.076,99$ & 3,29 & 10,4780 \\
\hline Norte & 31 & 14,01 & $73.701,28$ & 7,80 & 3,0894 \\
\hline Lorenzo Arenas & 9 & 4,19 & $19.268,60$ & 2,04 & 4,3246 \\
\hline Costanera & 1 & 0,45 & $4.067,67$ & 0,43 & 4,2194 \\
\hline Camino a Penco & 7 & 2,98 & $60.023,13$ & 6,35 & 1,8668 \\
\hline Nonguén & 14 & 6,48 & $97.802,41$ & 10,35 & 2,3530 \\
\hline Lonco & 24 & 10,75 & $63.443,92$ & 6,71 & 4,2065 \\
\hline Boca sur & 12 & 5,41 & $180.466,01$ & 19,09 & 0,5723 \\
\hline San Pedro & 31 & 13,95 & $120.168,36$ & 12,71 & 2,4973 \\
\hline Penco & 5 & 2,10 & $14.222,16$ & 1,50 & 1,6995 \\
\hline Lirquén & 1 & 0,45 & $2.114,68$ & 0,22 & 0,0134 \\
\hline Chiguayante & 34 & 15,15 & $177.598,31$ & 18,79 & 2,1995 \\
\hline Talcahuano Centro & 8 & 3,83 & $27.875,88$ & 2,95 & 3,4257 \\
\hline San Vicente & 2 & 0,92 & $3.920,23$ & 0,41 & 3,1375 \\
\hline Hualpén & 4 & 1,74 & $22.342,99$ & 2,36 & 2,3999 \\
\hline Higueras/Salinas & 9 & 3,94 & $47.160,28$ & 4,99 & 1,9016 \\
\hline \multirow[t]{3}{*}{ TOTAL } & 221 & 100,00 & $945.252,89$ & 100,00 & 2,4299 \\
\hline & & $\bar{x}$ & $5.464,75$ & $m^{2}$ & \\
\hline & & $\bar{x}$ & 0,55 & ha & \\
\hline
\end{tabular}

Fuente: Elaboración propia a partir de datos Boletines MSU/UBB.

ACE, 16 (4.6) CC BY-ND 3.0 ES | UPC Barcelona, España | Tendencias del mercado de suelo urbano en periodo 
Durante el período analizado, varios sectores pasaron por etapas de cambio en su estructura interna de precios (Lorenzo Arenas, Costanera, Nonguén, Boca Sur, Hualpén, Talcahuano Centro, San Vicente e Higueras/Salinas), vinculado a modificaciones en el destino urbano y uso del suelo motivadas por la presión de la dinámica propia de las actividades exportadoras, de nuevos proyectos inmobiliarios y por las iniciativas gubernamentales tales como infraestructura, programas de vivienda, modificaciones de los instrumentos de planificación urbana y descontaminación, creación de nuevas comunas (Chiguayante, San Pedro de la Paz y Hualpén).

También se registraron cambios a partir de accidentes de causa humana como el incendio en Bahía de San Vicente en 1993, impactos de la naturaleza como las inundaciones en sectores Concepción Centro, Lonco y Nonguén en 2006 y el terremoto en 2010 que afectó a toda la región y las aledañas (Araucanía y Maule). Dichos impactos afectaron los precios en los siguientes tres periodos trimestrales de análisis.

Cabe hacer presente que, en general, las variaciones se registran en una misma área urbana lo que evidencia algún grado de inestabilidad en el precio de oferta de suelo al interior de esa zona; pero ello obviaría algún posible error en la metodología. Aun así, y con las salvedades indicadas anteriormente, es posible establecer que la estructura de precios anunciada se caracteriza por tener cinco sectores en el tramo de precios menores (0,0 a 2,0 UFxm²), siete entre los precios medios (2,0 a 4,0 UFxm2) y cuatro entre los precios mayores (4,0 a 10,0 y más UFxm²).

Sin embargo, nueve de dieciséis sectores se encuentran en el rango de precios menores y medios menores (0,0 a 3,0 UFxm²). En el último tramo, de precios mayores, se debe hacer la distinción con el sector Concepción Centro, el cual se encumbra por sobre las 10,0 UF/m². (Tabla 4).

Tabla 4. Gran Concepción. Estructura de sectores según rango de precio promedio (UFxm²)

\begin{tabular}{|c|c|c|c|c|c|}
\hline 0,0 a 1,0 & 1,0 a 2,0 & 2,0 a 3,0 & 3,0 a 4,0 & 4,0 a 5,0 & $>10,0$ \\
\hline \multirow[t]{2}{*}{$\begin{array}{l}\text {-Boca Sur } \\
\text {-Lirquén }\end{array}$} & $\begin{array}{l}\text {-Camino a Penco } \\
\text {-Higueras/Salinas } \\
\text {-Penco }\end{array}$ & $\begin{array}{l}\text {-San Pedro } \\
\text {-Chiguayante } \\
\text {-Hualpén } \\
\text {-Nonguén }\end{array}$ & $\begin{array}{l}\text {-Norte } \\
\text {-San Vicente } \\
\text {-Talcahuano Centro }\end{array}$ & $\begin{array}{l}\text {-Lonco } \\
\text {-Lorenzo } \\
\text { Arenas } \\
\text {-Costanera }\end{array}$ & $\begin{array}{l}\text {-Concepción } \\
\text { Centro }\end{array}$ \\
\hline & & Medio menor & Medio mayor & & \\
\hline \multicolumn{2}{|c|}{ MENORES } & \multicolumn{2}{|c|}{ MEDIOS } & \multicolumn{2}{|c|}{ MAYORES } \\
\hline
\end{tabular}

Fuente: Elaboración propia.

En el tramo de precios mayores es necesario tener presente que de 4,0 a 5,0 UFxm², la mayor desviación standard del precio, respecto al promedio, hace una diferencia relevante entre los sectores Lorenzo Arenas y Costanera respecto de Lonco, ya que este último presenta un indicador menor y por lo tanto mayor estabilidad.

Como se muestra en las gráficas de la Figura 7 el incremento de los precios en zonas periurbanas, tradicionalmente de precios menores, puede indicar una cierta tendencia a la búsqueda de plusvalías por sustitución de sectores socioeconómicos. Es decir, comprar a precios periurbanos pobres y vender a precios destinados a sectores medios. (Norte, Nonguén, Boca Sur, Higueras/Salinas). 
Figura 7. Tendencia al incremento de precios en los periurbanos 1989-2018

Figura 7.1. Sector Norte

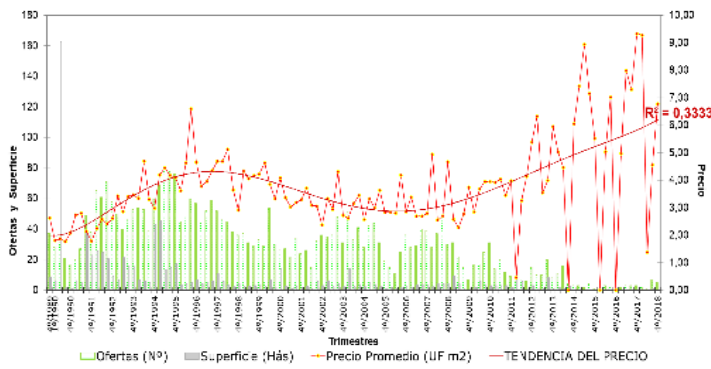

Figura 7.3. Sector Boca Sur

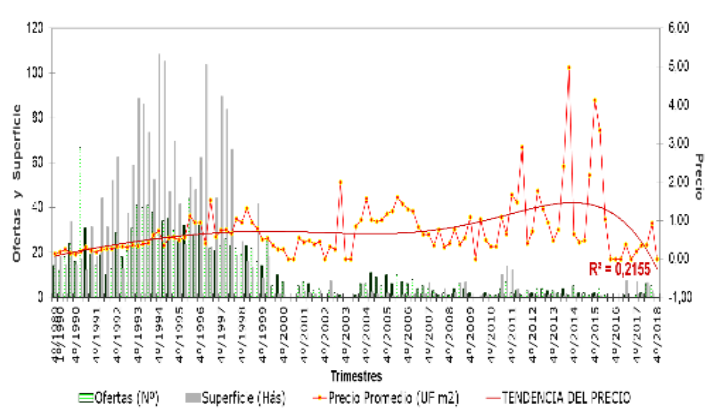

Figura 7.2. Sector Nonguén

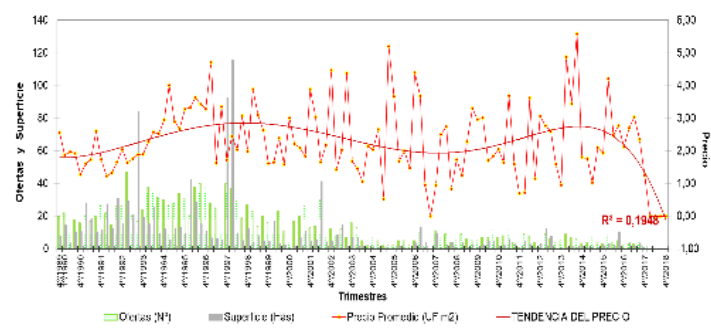

Figura 7.4. Sector Higueras / Salinas

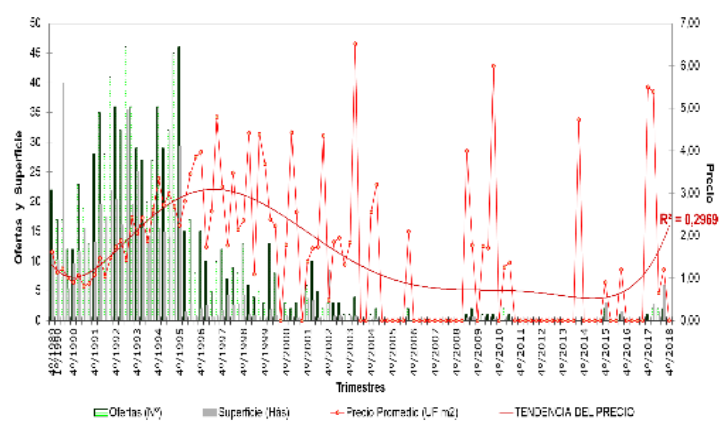

Fuente: Elaboración propia a partir de datos Boletines MSU/UBB.

\subsubsection{Respecto de la Cantidad de Ofertas}

Es evidente que el principal indicador de las ofertas es el precio, sin embargo, el número de lotes ofrecidos trimestre a trimestre evidencia, en función de su regularidad, una importante consolidación general del mercado, con un volumen de ofertas de relativa estabilidad (Figura 5 y Tabla 3)

Los sectores concentradores del número de ofertas fueron: Chiguayante (15,15\%); Norte (14,01\%); San Pedro (14,04\%); Concepción Centro (13,64\%) y Lonco (10,75\%), ya que juntos representan el 67,59\% del total. (Tabla 3)

En relación con los tamaños prediales la concentración fue persistente, sobre el 65\%, en los tramos menores que van desde 0 a $2.500 \mathrm{~m}^{2}$.

\subsubsection{Respecto de la Superficie Ofrecida}

Presenta también regularidades, aunque con una menor variación entre trimestres. La oferta de predios menores (hasta $5.000 \mathrm{~m}^{2}$ ) se presentó en los sectores Costanera, Penco, Talcahuano, San Vicente, Lonco, y Centro; y los predios mayores en Nonguén, Boca Sur, Chiguayante, e Higueras/Salinas, lo cual se relaciona con la antigüedad urbana bajo el proceso de subdivisión y edificación y la situación centro-periferia en que se localizan, además de que, respecto a la cantidad de ofertas, éstas se vinculan a los sectores de predios mayores. (Tabla 3).

ACE, 16 (4.6) CC BY-ND 3.0 ES | UPC Barcelona, España | Tendencias del mercado de suelo urbano en periodo 
La concentración (sobre 80\%) persiste en los tres tramos mayores que van desde 5.001 a 50.000 o más $\mathrm{m}^{2}$; es decir, inversamente a la cantidad de ofertas.

Los sectores Boca Sur (19,09\%), Chiguayante (18,79\%), San Pedro (12,71\%) y Nonguén (10,35\%), fueron concentradores de la superficie ofrecida; ya que juntos representaron el 60,94\% del total (Tabla 3).

Al respecto, una segunda reflexión nos lleva a que, si bien el comportamiento de los sectores sigue la lógica y ritmo del comportamiento global del mercado, ellos reflejan su dinámica particular en relación con sus caracterices propias urbano ambientales, demográficas y socioeconómicas.

La estructura de precios refleja importantes vinculaciones; por una parte, entre periferia y centro y, por otra, con la estructura económica de la ciudad. Ello indica, por cierto, que el precio del suelo tiende a reflejar la estratificación socioeconómica y que ésta presenta, además, las complejidades propias respecto a oferta y demanda de suelo derivadas de su tamaño demográfico, de su capacidad de pago y de su presión por localización, asunto válido tanto para las familias como para las instituciones y empresas. Este es un aspecto detectado también por Jojoa y Marmolejo para la ciudad de Bogotá. (Jojoa Villarraga \& Marmolejo Duarte, 2013). Es decir, la ciudad, en un mercado en el contexto de una economía neoliberal, refleja la desigualdad de ingresos en la localización segregada de los grupos sociales.

\section{Proyecciones}

Con el objetivo de auscultar el desarrollo de los mercados de suelo urbano en el Gran Concepción, realizamos un análisis de proyecciones al año 2030, (Figura 8), a partir del comportamiento anterior de las tres variables. Utilizamos el modelo de previsiones de Holt-Winters para series temporales de suavizamiento exponencial por su flexibilidad para adaptarse a cambios, tendencias y estacionalidad. (Hernández Suárez, 2015).

El resultado confirma la tendencia a la baja de la oferta de suelo en número y superficie. Por cierto, la proyección negativa es parte del ejercicio estadístico; porque lo probable es la tendencia a la estabilización en ambas variables, aunque mostrará ofertas de punta que quebraran la tendencia en algún trimestre especifico como se ha observado durante todo el periodo.

En relación con los precios la proyección al año 2030 nos indica tendencia al alza, un precio promedio de 5,2118 UFxm² a diciembre de ese año para toda el área de estudio. Lo que equivale a un 75,22\% mayor sobre el precio promedio (2,9744 UFxm²) de diciembre 2018, con un límite de confianza superior de 15,0740 UFxm². (un 406,79\% mayor sobre el precio a dic 2018) y uno inferior de 4,6503 UFxm². (un 56,34\% mayor sobre el precio dic 2018).

La reflexión atingente nos lleva a una dualidad importante de considerar. Por una parte, las proyecciones se realizan en función del comportamiento histórico de las variables involucradas por lo que no es posible asegurar que el comportamiento parcial por periodos y/o sectores tendrá, a su vez, un comportamiento igual. Por otra, a nivel de tendencia global es muy probable que, caeteris páribus el tipo y rol del Estado y las reglas de la economía neoliberal para el funcionamiento del mercado, las tendencias identificadas por proyección se ajusten a la realidad.

ACE, 16 (4.6) CC BY-ND 3.0 ES | UPC Barcelona, España | Tendencias del mercado de suelo urbano en periodo

largo. Concepción, Chile. 1989-2018. DOI: http://dx.doi.org/10.5821/ace.16.46.9946 
Figura 8. Proyecciones 2030
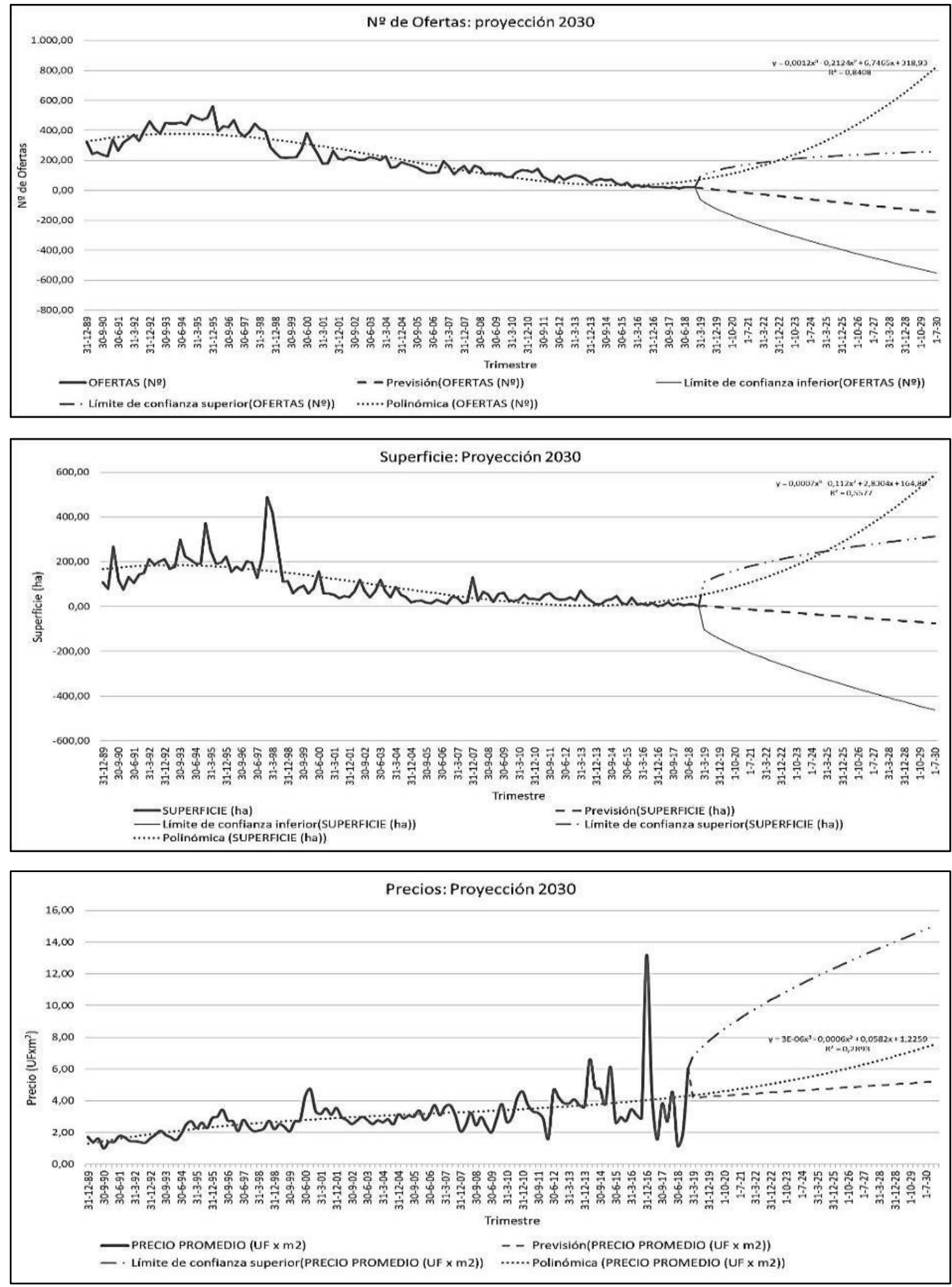

Fuente: Elaboración propia a partir de datos Boletines MSU/UBB. 


\section{Conclusiones}

El mercado de ofertas de suelo urbano en el Gran Concepción presenta un alto grado de consolidación, lo cual se demuestra tanto por la continuidad y persistencia del volumen de la oferta registrada desde el cuarto trimestre del año 1989, como por sus características relativas a precio, número de ofertas y superficie de las mismas vinculadas fuertemente a las condicionantes urbanas del área global y sectorial correspondiente. Esta constatación resulta determinante para sostener su confiabilidad.

Del comportamiento global del mercado en el área de estudio se concluye que este presenta flexibilidades observables por periodo; pero en un marco acotado por bandas de valores que tienden al alza respecto del precio y a la baja en cantidad y superficie. Es decir, en mercados abiertos de corte liberal o neoliberal los precios fluctúan, en lo general, en función de las fuerzas de oferta y demanda y no necesariamente en virtud de las políticas de desarrollo urbano. Por su parte, los impactos derivados de desastres alteran fuertemente el comportamiento de dichas bandas de precio.

La estructura de sectores en función de los precios refleja importantes vinculaciones con la dinámica de resultados de la economía y la estructura socioeconómica espacial que esa dinámica imprime en la ciudad. De allí es posible deducir que, en el modelo económico vigente en Chile, los precios siguen la estratificación funcional, económica y socioeconómica de la aglomeración ya que el acceso al suelo urbano es función de la capacidad de ingresos de las instituciones, empresas y personas. Pero también es posible establecer que el precio del suelo tiende a reflejar la estructura urbana y que ésta presenta las complejidades propias de su tamaño respecto a oferta y demanda de suelo en el marco de las reglas de la economía imperante en el territorio.

La participación de los sectores en la cantidad de ofertas (número) sigue la tendencia del proceso de subdivisión y densificación de la estructura urbana, constituyendo un antecedente importante para identificar las áreas más dinámicas de la aglomeración. Para el área global del Gran Concepción, se constató que esta variable no se vincula estrictamente a alguna distribución del tipo centro-periférica de los sectores como pudiere estimarse en principio.

Se detectó que la participación de los sectores en la superficie ofrecida presenta una doble característica. Por una parte, sigue la tendencia del proceso de subdivisión y densificación de la estructura urbana tal como en el número de ofertas y, por otra, se vincula a las áreas periféricas de expansión que concentran preferentemente los programas gubernamentales de vivienda y, secundariamente, los desarrollos inmobiliarios privados en sectores demandados por grupos socioeconómicos mayores consolidados o emergentes.

Si bien el comportamiento de los sectores sigue la lógica y ritmo del comportamiento global del mercado, los mismos reflejan su dinámica particular en relación con sus caracterices propias urbano ambientales, demográficas y socioeconómicas.

Por otra parte, el grado de asociación de los datos entre las variables en el estudio a escala global, medido a través de coeficientes de correlación de Pearson (R), Kendall (Tau-b) y Spearman (Rho) para el período estudiado, posibilita confirmar que la cantidad de ofertas y la superficie ofrecida presentaron fuerte grado de asociación positiva por lo que tienden a aumentar la una con el aumento de la otra. El precio también se asoció significativamente, aunque en forma inversa tanto con el número de ofertas como con la superficie ofrecida, disminuyendo al aumentar aquellas.

El Gran Concepción como unidad urbana y la mayoría de los sectores en su interior, registraron notoriamente los impactos del ciclo de baja de la economía a partir del segundo trimestre de 1996 y

ACE, 16 (4.6) CC BY-ND 3.0 ES | UPC Barcelona, España | Tendencias del mercado de suelo urbano en periodo

largo. Concepción, Chile. 1989-2018. DOI: http://dx.doi.org/10.5821/ace.16.46.9946 
hasta el cuarto trimestre de 1999, derivado de las fuerte turbulencias por la crisis de los países emergentes en el sudeste asiático. Se apartaron de este comportamiento cíclico los sectores Chiguayante, San Pedro, Costanera y Boca Sur, lo cual se debe, en los primeros dos casos, a las expectativas derivadas de la creación de las nuevas comunas las que, por cierto, se reflejan en el mercado antes de la decretación jurídica formal y, en los dos casos siguientes, a proyectos gubernamentales específicos como el Plan Ribera Norte del río Biobío en el sector Costanera y a los programas públicos de vivienda en el sector Boca Sur. Del mismo modo, el desacople de los precios y la dinámica de la economía, entre el primer trimestre de 2010 y el segundo de 2016, coincide con el impacto producido por el terremoto y tsunami del 27 de febrero 2010.

Ello implica que no es sólo la ley de oferta y demanda directa actuando temporalmente al unísono con las ofertas y transacciones en el mercado, sino que actúan otros dos componentes claves como es la pre-configuración del precio o "precio adelantado" ante los anuncios gubernamentales y el "precio de impacto" debido a desastres tanto de la naturaleza como por acción humana.

Otro hallazgo relevante se observa debido al desacople definitivo de las variables número de ofertas y superficie ofrecida con respecto al precio, desde el cuarto trimestre del 2008 para el caso de las ofertas y desde el segundo trimestre de 1995 para la superficie ofrecida. Lo anterior confirma la robustez del mercado porque las expectativas de precio operan, en lo general, regularmente en la elasticidad oferta y demanda.

Aunque influyen casos específicos, como fue la oferta de un terreno de 154 ha. en junio de 1990, o los pick en número de ofertas y superficie en algunos trimestres de los años 1993-1994 y 1997-19982002-2004 y 2008; se detectan tendencias cíclicas por estacionalidad en el precio de oferta, por cuanto se verifica cierta depresión en verano (primer trimestre) y en invierno (tercer trimestre), posiblemente debido a la concentración en ciclos trimestrales de las transacciones efectivamente realizadas en el mercado.

Finalmente, es posible adelantar que parece ser que opera un mecanismo adicional para determinar la robustez del mercado asociado al momento (o al periodo) en que se verifica el desacople de variables claves como el precio, respecto de la oferta en cantidad y/o volumen. Por cierto, ambos aspectos podrían motivar nuevas líneas de investigación en territorios diversos.

Se espera que los aportes de información, metodología y hallazgos puedan servir de base a futuros estudios, en especial, para la relación entre espacio territorial metropolitano y mercado; mercado del suelo, cohesión e integración social; gobernanza y mercado del suelo; recuperación de plusvalías por acción pública y mercado del suelo. Cuatro asuntos que se estiman esenciales para el desarrollo nacional en Chile y Latinoamérica.

Las limitaciones esenciales en el período se produjeron en los momentos de importantes desastres como los que se mencionaron (incendio en los años 90, inundaciones 2006 y terremoto 2010) ya que, por una parte, dificulta la verificación en terreno de registros con información incompleta y; por otra, el mercado refleja la crisis ralentizando sus operaciones, lo que afecta la investigación por información limitada al reducirse el número de registros, seguidas de fuertes caídas de precios derivadas de la contracción de la oferta. Sin embargo, una vez anunciados los planes de mitigación gubernamentales se abren las expectivas y el ritmo del mercado tiende a reactivarse.

Evidentemente, las hipótesis adelantadas en la investigación, en cada caso, son preliminares y pueden ser modificadas incorporando otros estudios y consideraciones: territorio, rol del Estado, modelo económico, actores del mercado inmobiliario, entre otros.

ACE, 16 (4.6) CC BY-ND 3.0 ES | UPC Barcelona, España | Tendencias del mercado de suelo urbano en periodo

largo. Concepción, Chile. 1989-2018. DOI: http://dx.doi.org/10.5821/ace.16.46.9946 


\section{Agradecimientos}

El autor agradece a la Universidad del Bío-Bío (UBB), Concepción-Chile, a su Facultad de Arquitectura, Construcción y Diseño, su Depto. de Planificación y Diseño Urbano y al Laboratorio de Estudios Urbanos; por el aporte relevante y continuo a la investigación sobre mercado del suelo urbano. Un reconocimiento especial al doctor arquitecto Josep Roca Cladera, impulsor clave de la investigación base del articulo; al doctor Pablo Trivelli Oyarzún, economista, colaborador en los orígenes del estudio y a los integrantes del grupo líder del proyecto de investigación inicial: arquitectos Roberto Goycoolea Infante (QEPD), Premio Nacional de Arquitectura, Ex Rector UBB; Waldo Martínez Riquelme, ex Director División de Desarrollo Región del Biobío; Dr. Arq. Rodrigo García Alvarado, ex Director Doctorado Arquitectura y Urbanismo, Director Dpto. Diseño y Teoría de la Arquitectura UBB; a los estudiantes y profesionales miembros del equipo de producción del Boletín Mercado de Suelo Urbano en el Gran Concepción, que actuaron en las diversas etapas a lo largo de los años, hoy destacados profesionales: Henri Jarpard Enriquez, Marco Medero, Luis Antonia Molina Campos, Alejandro Cerda Brintrup; Hernán Barría Chateau, Pauline Trebilcock Kelly, Eleodoro Mora Ariz, Gonzalo Iturra Soto; a Juan Espinoza Cid, especialista en SIG del Laboratorio de Estudios Urbanos UBB y al Dr. Arq. Gonzalo Cerda Brintrup, del Dpto. Diseño y Teoría de la Arquitectura UBB. Por cierto, mi agradecimiento a los revisores del manuscrito cuyos aportes contribuyeron al perfeccionamiento y calidad de la versión definitiva.

Conflicto de intereses: El autor declara que, tanto respecto de la metodología utilizada, del origen y tratamiento de los datos, así como de la conceptualización desarrollada, no hay conflicto de intereses.

\section{Bibliografía}

Abramo, P. (2012). La ciudad com-fusa: Mercado y producción de la estructura urbana en las grandes metropolis latinoamericanas. EURE: Revista latinoamericana de estudios urbano regionales, 38(114), 35-69. DOI: https://doi.org/10.4067/S0250-71612012000200002

Alcazar Molina, M. G. (2008). Mercado inmobiliario y catastro. Revista de Derecho Urbanístico y Medio Ambiente, 244, 11-64.

Arellano, B., \& Roca, J. (2013). Plusvalías y regeneración urbana. El caso de estudio del Centro Histórico de Guadalajara. Congreso Internacional Ciudad y Territorio Virtual, 1083-1097. Recuperado de http://hdl.handle.net/2099/16407

Daher, A. (1991). Neoliberalismo urbano en Chile. Revista Estudios Públicos, 43, 281-299. Recuperado de https://www.cepchile.cl/cep/site/artic/20160303/asocfile/20160303184631/rev43 daher.pdf

Furtado, F. (1997). Instrumentos para la recuperación de plusvalías en América Latina: Debilidades en la implementación, ambigüedad en la interpretación. Lincoln Institute Research Report. Recuperado de

http://scholar.google.com/scholar?hl=en\&btnG=Search\&q=intitle:Instrumentos+para+la+Recuperació $\underline{n+d e+P l u s v a l i ́ a s+e n+A m e ́ r i c a+L a t i n a:+D e b i l i d a d+e n+l a+I m p l e m e n t a c i o ́ n,+A m b i g u ̈ e d a d+e n+l a+I n t e r p ~}$ retación\#0

Gaete-Feres, H. (2003). Gestión del urbanismo y administración urbana: los pies de barro en el despliegue territorial del neoliberalismo en Chile. Revista de Urbanismo, 4(07), 20-38. Recuperado de http://www.doaj.org/doaj?func=openurl\&issn=07175051\&date $=2003 \&$ volume $=4 \&$ issue $=07 \&$ spage $=20 \&$ genre=article

Gasic, I. (2018). Inversiones e intermediaciones financieras en el mercado del suelo urbano. Principales hallazgos a partir del estudio de transacciones de terrenos en Santiago de Chile, 2010-2015. EURE (Santiago), 44(133), 29-50. DOI: https://doi.org/10.4067/s0250-71612018000300029

ACE, 16 (4.6) CC BY-ND 3.0 ES | UPC Barcelona, España | Tendencias del mercado de suelo urbano en periodo

largo. Concepción, Chile. 1989-2018. DOI: http://dx.doi.org/10.5821/ace.16.46.9946 
Gobierno_Chile. Proyecto Ley de Integración Social y Urbana (2018). Chile. Recuperado de https://www.camara.cl/pley/pley detalle.aspx?prm|D=12802\&prmBoletin=12288-14

Harvey, D. (2018). The urban process under capitalism: A framework for analysis. En Urbanization and Urban Planning in Capitalist Society. Nueva York, EEUU. DOI: https://doi.org/10.4324/9781351068000

Hernandez, H. (1983). El Gran Concepción: Desarrollo histórico y estructura urbana. Revista Informaciones Geográficas, 30, 3-4.

Hernández Suárez, C. A. (2015). Análisis de una serie de tiempo utilizando diseño de experimentos como herramienta de calibración. Ecomatemático, 6(1), 50-61. DOI: https://doi.org/10.22463/17948231.459

INE_Chile, Instituto Nacional de Estadisticas. (2018). SÍNTESIS RESULTADOS DE CENSO 2017. sec 1.1. Stgo. Chile. Recuperado de www.ine.cl

INE_Chile, Instituto Nacional de Estadísticas. (2019). Estadísticas Económicas Regionales. Recuperado de https://www.ine.cl/estadisticas/economicas/economicas-regionales

Jaramillo, S. (2009). Algunos instrumentos de gestión del suelo. En Hacia una teoría de la renta del suelo urbano (pp. 331-349). ISBN: 9789586953658, pp. 445, Ediciones Uniandes, Bogotá.

Jojoa Villarraga, J. P., \& Marmolejo Duarte, C. (2013). Evaluación del impacto de la estratificación socioeconómica en la formación del valor del suelo en bogotá D.C. ACE: Architecture, City and Environment, (23), 95-124. DOI: https://doi.org/10.5821/ace.8.23.2598

Laboratorio Biociudades Minvu_Seremi Biobío. (2018). Consumo de Suelo, de la región del Biobío Laboratorio Biociudades. Recuperado de http://laboratoriobiociudades.minvu.gob.cl/2018/02/16/consumo-de-suelo-de-la-region-del-biobio/

Lincoln Institute. (2018). Lincoln Institute launches global campaign to promote land value capture | Lincoln Institute of Land Policy. Recuperado de https://www.lincolninst.edu/es/news/lincoln-houseblog/lincoln-institute-launches-global-campaign-promote-land-value-capture

MINVU_Chile. LEY NÚM. 21.078 SOBRE TRANSPARENCIA DEL MERCADO DEL SUELO, Creative Commons $\S$ (2018). Chile. Recuperado de http://bcn.cl/23sec

Morales Schechinger, C. H. (2005). Políticas de suelo urbano, accesibilidad de los pobres, y recuperación de plusvalías. En La renta del suelo, las finanzas urbanas y el municipio mexicano (pp. 1-38). Recuperado de http://www.fcp.uncu.edu.ar/upload/morales-schechinger-2005.PDF

Moreno, L. (2014). The urban process under financialised capitalism. City, 18(3). DOI: https://doi.org/10.1080/13604813.2014.927099

OCDE. Estudios Económicos de la OCDE 2018, 1 Estudios Económicos de la OCDE § (2018). Recuperado de http://www.oecd.org/eco/surveys/Chile-2018-OECD-economic-sruvey-Spanish.pdf

OCDE, Estudios Económicos de la OCDE 2019, 1 Estudios Económicos de la OCDE § (2019). Recuperado de https://www.oecd.org/chile/sag2019-chile-es.pdf

OECD. (2020). ¿Cómo va la vida en Chile? En How's Life? 2020: Midiendo el bienestar. Publicaciones de la OCDE. DOI: https://doi.org/10.1787/e281c29a-es

Sabatini, F. (1990). Precios del suelo y edificación de viviendas (4 conclusiones sobre Santiago relevantes para políticas urbanas ). EURE (Santiago), XV/(49), 63-72. Recuperado de https://www.eure.cl/index.php/eure/article/view/1036/738

Smolka, M., \& Amborski, D. (2003). Recuperación de plusvalías para el desarrollo urbano: una comparación inter-americana. Eure, 29(88), 55-77. DOI: https://doi.org/10.4067/S0250$\underline{71612003008800003}$

ACE, 16 (4.6) CC BY-ND 3.0 ES | UPC Barcelona, España | Tendencias del mercado de suelo urbano en periodo

largo. Concepción, Chile. 1989-2018. DOI: http://dx.doi.org/10.5821/ace.16.46.9946 
Smolka, M. O. (2012). Una nueva mirada a la recuperación de plusvalías en América Latina. cambridge (massachusetts). Recuperado https://www.lincolninst.edu/sites/default/files/pubfiles/2137 1462 Una nueva mirada a la recuper acion de plusvalias 0712LLSP.pdf

Theodore, N., Peck, J., \& Brenner, N. (2009). Urbanismo neoliberal: la ciudad y el imperio de los mercados. Temas Sociales SUR, (66), 12. Recuperado de www.sitiosur.cl

Trivelli, P. (2010). Urban structure, land markets and social housing in Santiago, Chile. Recuperado de https://cafedelasciudades.com.ar/imagenes109/012411\%20Informe\%20final PTrivelli.pdf

Vejarano, M. C. (2008). Bogotá, D.C. Primera Experiencia De Recuperación De La Plusvalía Urbana Para La Colectividad, En El Marco De La Ley De Desarrollo Territorial. Ace. DOI: http://dx.doi.org/10.5821/ace.v3i7.2440

Vergara-Perucich, F., \& Aguirre-Núñez, C. (2020). Simulación de recuperación de plusvalía urbana para Línea 3 del Metro de Santiago. ACE: Architecture, City and Environment, 14(42). DOI: https://doi.org/10.5821/ace.14.42.8963

Viloria, L. S. (2011). Una aproximación hedónica al efecto de las preferencias por segregación en el precio del suelo urbano en Bogotá * A Hedonic Approach to the Effect of Preferences for Segregation in Urban Land Prices in Bogota Introducción. Equidad \& Desarrollo, 139-162. https://doi.org/10.19052/ED.140

Winchester, L. (2008). La dimensión económica de la pobreza y precariedad urbana en las ciudades latinoamericanas. Implicaciones para las políticas del hábitat. Revista EURE, XXXIM(103), 27-47. https://doi.org/10.4067/S0250-71612008000300002 